\title{
CONTRIBUIÇÕES DE TEORIAS DO ENSINO DA ARTE PARA A DOCÊNCIA DE HISTÓRIA DA ARTE NO NÍVEL SUPERIOR: REFLEXÕES SOBRE EXPERIÊNCIAS
}

Rita de Cássia Demarchi ${ }^{1}$

\section{Resumo}

Este trabalho busca compartilhar reflexões e metodologias advindas da docência da disciplina História da Arte junto a alunos de cursos nas áreas de Arte e Desenho Industrial em uma faculdade particular da cidade de São Paulo, nos anos de 2002 a 2005.

A grande maioria dos alunos demonstrou inicialmente pouca familiaridade com a História da Arte e a principal expectativa em relação ao curso era a de aquisição de meios para reconhecer estilos e obras. Esse fato suscitou questionamentos: Como levar os alunos a perceberem que a apreciação vai muito além do mero reconhecimento? Como favorecer as relações entre as suas próprias vivências e os saberes da História da Arte, sem cair em uma visão reducionista?

As reflexões acerca da mediação da arte (Martins, 2001) levaram a docente à busca de metodologias que visassem a experiência estética (Dewey, 1980) e conseqüentemente, a interação dos alunos com conteúdos desconhecidos pela grande maioria, rumo à construção de um saber sensível e significativo (Maffesoli, 1998 e Duarte, 2001). Com base na Fenomenologia, antes de trabalhar com conceitos dos teóricos da História da Arte, realizaram-se experiências de leitura de obra (metodologia de Ott), onde foi valorizada a percepção primeira dos alunos sobre as imagens.

O desenvolvimento do trabalho indica que essas teorias do Ensino de Arte se mostraram como possibilidades enriquecedoras para a docência de História da Arte, e merecem investigação aprofundada acerca de suas possibilidades.

Palavras-chave: História da Arte - Ensino de Arte - nível superior de ensino.

Este trabalho busca compartilhar reflexões e metodologias advindas da docência da disciplina História da Arte nos cursos de Educação Artística - Licenciatura em Artes Plásticas e Bacharelado em Desenho Industrial em uma faculdade particular da cidade de São Paulo, no período compreendido entre os anos de 2002 a 2005.

Constato que a minha formação acadêmica (Licenciatura, Especialização e Mestrado) na área de Ensino de Arte, assim como as experiências profissionais anteriores contaminaram sensivelmente as investigações na docência de História da Arte. Gradativamente, tornei-me mais consciente do papel de mediadora de uma área do conhecimento junto a determinados grupos, e não apenas transmissora de um saber erudito e cristalizado, por mais interessante e sedutor que este possa se mostrar.

A Arte é um campo de estudo fascinante e profundo. Diversos teóricos se dedicam a aproximá-la do público leigo, sem deixar de apontar algumas questões indicadoras de sua complexidade enquanto área do conhecimento. Entre eles está Jorge Coli, que abre o livro O que é Arte (2000, p.7) com a afirmação: "Dizer o que seja a arte é coisa difícil".

Some-se a esse outro ponto: à medida que a produção artística se aproxima dos nossos dias, o terreno que dá sustentação às discussões parece se mostrar cada vez mais instável e movediço. A situação não parece confortável nem mesmo para os estudiosos e especialistas...

1 UNESP/ FPA/ FAMEC 
Por vezes, em sala de aula, é visível a angústia dos estudantes que iniciam seus estudos na área, quando notam a abrangência do universo que adentram, dividido em diversas disciplinas teóricas e práticas. Há tanto para ser visto, estudado, construído e refletido e aparentemente, tão pouco que possa ser enquadrado em conceitos fechados e precisos! (Lembro-me bem quando iniciei a graduação, não faz tanto tempo...).

Penso que, dependendo da abordagem, logo nos primeiros semestres a disciplina História da Arte pode ser vista como um saber mais "tranqüilo" e "linear", representando um porto seguro.

Acredito que utilizar essencialmente um método de ensino com projeção de imagens e explicações do professor sobre as obras, alicerçado por textos de autores consagrados ou esquemas simplificados é um meio seguro, mas de certa forma distanciado, talvez insuficiente para provocar as "experiências estéticas" apresentadas por Dewey (1980, p.90). Segundo o autor, a vida humana se dá na abertura do indivíduo ao mundo e é composta por experiências profundas que integram ação, sentimento e significação e possuem caráter estético, lidando ou não com objetos artísticos propriamente ditos.

Outros limites, referentes à instituição de ensino entram em questão: a disciplina é essencialmente teórica, sua ementa e a organização dos conteúdos segue um modo linear, onde constam os períodos a serem estudados dispostos em ordem cronológica. Por fim, há grande dificuldade de viabilizar saídas com grupos de alunos para visitar museus e exposições. Portanto, as possibilidades se restringem à sala de aula, com apreciação das reproduções das obras.

Como mediadora, as buscas se dariam no sentido de facilitar encontros significativos entre a linguagem da arte e o público. Mirian Celeste Martins amplia a idéia do mediador enquanto "ponte", ao mostrar um novo aspecto da mediação, onde se configura uma rede de conexões que envolvem, além do apreciador, do mediador e da obra, seus diferentes âmbitos:

\footnotetext{
... a mediação hoje ganha um caráter rizomático, isto é, num sistema de interrelações fecundas e complexas que se irradiam entre o objeto do conhecimento, $o$ aprendiz, o professor/mediador/monitor, a cultura, a história, o artista, a instituição cultural, a escola, a manifestação artística, os modos de divulgação, as especificidades, os códigos, materialidades e suportes de cada linguagem artística... (2002, p.57).
}

Nessa perspectiva, o ato de mediar abarca um olhar amplo, continente, que abrange a obra, quem a olha e o seu olhar, assim como a própria mediação. Faz-se necessário olhar cuidadosamente para o grupo, seus repertório vivencial e cultural, assim como os seus anseios e dificuldades.

Apesar da grande maioria dos alunos ter demonstrado inicialmente pouca familiaridade com História da Arte, de maneira geral se mostravam curiosos e receptivos frente à disciplina. Assim como, alguns se desculpavam por "não saberem nada". Alheios às possibilidades de em do mero reconhecimento? Como favorecer as relações entre as suas próprias vivências e os saberes da História da Arte, sem cair em uma visão reducionista?

Ao longo dos semestres letivos, foi tomando corpo uma metodologia para apresentação do curso e da turma no primeiro dia de aula. Metodologia essa bastante simples, mas que procura instigar e provocar diálogos entre as obras e a vivência dos alunos: a proposta de apresentação por meio de uma imagem. 
Reproduções de obras de diversos períodos da História da Arte são espalhadas pelo chão da sala de aula. Algumas das imagens são conhecidas do grande público, tais como pinturas de Leonardo Da Vinci, Monet, Van Gogh e Tarsila do Amaral. Outras são bem menos conhecidas, e indicam outros suportes além da pintura e escultura, como no caso de objetos da arte contemporânea.

A proposta é de que cada aluno aprecie o conjunto e escolha uma imagem para se apresentar ao grupo. Ressalto que não é necessário "ter conhecimento" sobre a obra, saber quem é o artista, qual é o período, etc; e que o mais importante no momento é o impacto da imagem, é o que ela provoca no indivíduo: afinidade, prazer, curiosidade, inquietação, recordações... Em um segundo momento, cada um comenta para os outros integrantes os porquês de sua escolha, as relações entre a imagem escolhida e a sua vida.

Verificou-se, na maioria absoluta das vezes, que a proposta transcorreu com facilidade, gerando interesse e participação dos grupos. Ao serem valorizadas as conexões estabelecidas, a idéia era de evidenciar que cada ser humano carrega consigo um grande repertório de conhecimento, composto não apenas pelo saber erudito e racional, mas também por sua bagagem experencial, pelo sensível. Nesse sentido, a percepção é fundamental.

A valorização da percepção primeira sobre as imagens tem como base a Fenomenologia, que segundo Merleau-Ponty (1971) é uma ciência que "propõe um retorno às coisas mesmas", ou seja, encarar a realidade como fenômeno que deve ser analisado tal como é, antes de se apegar ao conhecimento racional ou científico. Não se trata de voltarse para dentro de si, para o interior da consciência, uma vez que esta não pode ser deslocada do mundo, ela se dá no mundo:

Tudo o que sei do mundo, mesmo devido à ciência, o sei a partir de minha visão pessoal ou de uma experiência de mundo sem a qual os símbolos da ciência nada significariam. Todo o universo da ciência é construído sobre o mundo vivido e se quisermos pensar na própria ciência com rigor, apreciar exatamente o seu sentido e o seu alcance, convém despertarmos primeiramente esta experiência do mundo da qual ela é expressão segunda (1971, p.6).

Através de nossa sensibilidade e percepção, nos alimentamos de sensações que são colhidas no ato de "viver no mundo", desde o nascimento e ao longo de toda a vida. As sensações decorrentes desta experiência do mundo, esse saber primeiro, intimamente ligado ao objeto é chamado por Duarte de "saber sensível" (2001, p. 12)

Maffesoli (1998) é outro autor que trabalha com algumas idéias de Merleau-Ponty, de modo a ressaltar os aspectos de encontro entre a sensibilidade e o intelecto. Contrário a radicalismos, Maffesoli propõe o abandono do racionalismo ou do irracionalismo dissociados. Promove a sua fusão, que alargaria e aprofundaria o pensamento humano, por meio da "razão sensível".

A proposta de apresentação dos alunos por meio de imagens também tem se mostrado um valioso recurso de avaliação diagnóstica dos grupos. Sem se sentirem pressionados pelo peso do saber científico, são expressos de maneira mais espontânea os seus gostos, preferências, repertório cultural, sendo que a fala e vocabulário empregados desvelam também conceitos, preconceitos e valores acerca da Arte. Esses dados enriquecem a minha percepção do grupo, alimentando a minha atuação como mediadora, ao longo do semestre.

No decorrer do curso, seguindo o arcabouço teórico citado anteriormente, buscouse continuar o trabalho de estimular a sensibilidade e valorizar a percepção primeira dos 
alunos sobre as obras. A este "saber sensível" é somado o saber erudito da História da Arte, com base em autores referenciais como E.H. Gombrich, J. Janson e G. C. Argan.

A fim de instigar a percepção e uma leitura mais rica da obra de Arte, uma adaptação da metodologia "Image Watching" de Robert Ott tem se mostrado adequada, uma vez que compactua com as concepções acima.

"Image Watching" é um método elaborado nos Estados Unidos, nos anos oitenta. No Brasil, é divulgado especialmente por Ana Mae Barbosa (1997) e Christina Rizzi (2000). Trabalhos no MAC/USP, Museu de Arte Contemporânea da USP e no Museu Lasar Segall também carregam a sua influência.

"Image Watching" é organizado em seis etapas, bem definidas e articuladas. Por meio de perguntas, cabe ao mediador levar o fruidor à reflexão e conduzir a mediação, obedecendo à seqüência pré-estabelecida. $\mathrm{O}$ processo se inicia com o Aquecimento, que consiste em uma sensibilização frente à obra, preparando uma atmosfera favorável à percepção da obra.

Em seguida, as etapas da mediação propriamente dita são:

. Descrevendo, que levanta questões sobre a percepção primeira e enumeração do que está sendo visto.

- Analisando é a etapa em que é feita uma análise do ponto de vista formal e técnico da obra, ainda se refere ao que está sendo visto de fato na obra.

. Interpretando: levanta-se informações mais subjetivas referentes ao que a obra despertou no fruidor. Aqui entram as sensações, sentimentos, significados.

. Fundamentando: o mediador trabalha com a ampliação de informações sobre a obra, o artista, e a sua contextualização.

Revelando: o fruidor revela no fazer artístico o conhecimento por ele construído/vivenciado no decorrer da experiência.

Contudo, a adaptação do método junto aos alunos da graduação pressupõe uma atitude de abertura e flexibilidade, sem a rigidez de seguí-lo etapa por etapa, na seqüência determinada. Detive-me ao aspecto de que as informações objetivas sobre a obra são colocadas somente depois de instigadas a percepção primeira, a análise formal e as interpretações subjetivas do grupo.

A percepção primeira não é classificada como certa ou errada, tudo é pertinente e isto parece aliviar e descontrair aqueles que dizem "não saber nada" sobre História da Arte. Enquanto escrevo e reflito sobre esse trabalho, considero o envolvimento das turmas como um indicador positivo e relembro falas significativas dos alunos e as suas relações criativas, reveladoras de um contato íntimo com a obra (ainda que seja com uma reprodução da obra).

A partir dessas considerações, acredito que o assunto requer uma pesquisa mais sistematizada. As propostas advindas da área de Ensino de Arte se mostraram como possibilidades enriquecedoras para a docência de História da Arte e indicam merecer uma investigação aprofundada acerca de suas potencialidades.

\section{Bibliografia}

COLI, Jorge.O que é arte. São Paulo: Brasiliense, 2000.(15.ed.)

DEMARCHI, Rita de Cássia. Encontros Sensíveis: experiências de mediação da obra pública Estação Sumaré no metrô de São Paulo. São Paulo, 2003. Dissertação (Mestrado). Instituto de Artes/UNESP. 
DEWEY, John. A arte como experiência. São Paulo: Abril Cultural, 1980 (Coleção Os Pensadores)

DUARTE, João Francisco Jr. O sentido dos sentidos : a educação (do) sensível. Curitiba: Criar Edições, 2001.

MAFFESOLI, Michel. Elogio da razão sensível. Petrópolis: Vozes, 1998.

MARTINS, Mirian Celeste. Aquecendo uma transforma-ação: atitudes e valores no ensino de arte. In: BARBOSA, Ana Mae. Inquietações e mudanças no ensino da arte. São Paulo: Cortez, 2002.

MERLEAU-PONTY, M. Fenomenologia da Percepção. Trad. Reginaldo di Piero. Rio de Janeiro: Freitas Bastos, 1971

OTT, Robert Wilson. Ensinando crítica nos museus. In: BARBOSA, Ana Mae. Arte educação: leitura do subsolo. São Paulo, Cortez, 1997.

RIZZI, Christina. Contemporaneidade (mas não onipotência) do Sistema de

Leitura de Obra de Arte - Image Watching. In: Boletim Arte na escola. São Paulo: Fundação Iochpe, $n^{\circ}$ 22, março 2000. 